Article

\title{
An Earliest Endosymbiont, Wolbachia massiliensis sp. nov., Strain PL13 from the Bed Bug (Cimex hemipterus), Type Strain of a New Supergroup T
}

\author{
Younes Laidoudi 1,2 $\mathbb{D}$, Anthony Levasseur 1,2, Hacène Medkour 1,2 ${ }^{\mathbb{D}}$, Mossaab Maaloum ${ }^{3}$, \\ Mariem Ben Khedher 1,2, Masse Sambou 4,5 ${ }^{1}$, Hubert Bassene ${ }^{4,5}$, Bernard Davoust ${ }^{1,2}(\mathbb{D}$, \\ Florence Fenollar ${ }^{2,4}$, Didier Raoult ${ }^{1,2}$ and Oleg Mediannikov 1,2,*(D) \\ 1 Aix Marseille Univ, IRD, AP-HM, MEPHI, 13385 Marseille, France; younes.laidoudi@yahoo.com (Y.L.); \\ anthony.levasseur@univ-amu.fr (A.L.); hacenevet1990@yahoo.fr (H.M.); \\ mariem.ben-khedher@etu.univ-amu.fr (M.B.K.); bernard.davoust@gmail.com (B.D.); \\ didier.raoult@gmail.com (D.R.) \\ 2 IHU Méditerranée Infection, 13385 Marseille, France; florence.fenollar@univ-amu.fr \\ 3 Laboratory of Biology and Health, Faculty of Sciences Ben M'sik, Hassan II University, Sidi Othmane, \\ Casablanca 7955, Morocco; momossaab@gmail.com \\ 4 Aix Marseille Univ, IRD, AP-HM, SSA, VITROME, Marseille, France, 13385 Marseille, France; \\ massezorro1@gmail.com (M.S.); Hubert.Bassene@ird.fr (H.B.) \\ 5 Campus Commun UCAD-IRD of Hann, Dakar 10200, Senegal \\ * Correspondence: olegusss1@gmail.com
}

Received: 5 October 2020; Accepted: 23 October 2020; Published: 29 October 2020

\begin{abstract}
The symbiotic Wolbachia are the most sophisticated mutualistic bacterium among all insect-associated microbiota. Wolbachia-insect relationship fluctuates from the simple facultative/parasitic to an obligate nutritional-mutualistic association as it was the case of the bedbug-Wolbachia from Cimex lectularius. Understanding this association may help in the control of associated arthropods. Genomic data have proven to be reliable tools in resolving some aspects of these symbiotic associations. Although, Wolbachia appear to be fastidious or uncultivated bacteria which strongly limited their study. Here we proposed Drosophila S2 cell line for the isolation and culture model to study Wolbachia strains. We therefore isolated and characterized a novel Wolbachia strain associated with the bedbug Cimex hemipterus, designated as wChem strain PL13, and proposed Wolbachia massiliensis sp. nov. strain wChem-PL13 a type strain of this new species from new supergroup T. Phylogenetically, T-supergroup was close to F and S-supergroups from insects and D-supergroup from filarial nematodes. We determined the 1,291,339-bp genome of wChem-PL13, which was the smallest insect-associated Wolbachia genomes. Overall, the wChem genome shared 50\% of protein coding genes with the other insect-associated facultative Wolbachia strains. These findings highlight the diversity of Wolbachia genotypes as well as the Wolbachia-host relationship among Cimicinae subfamily. The $w$ Chem provides folate and riboflavin vitamins on which the host depends, while the bacteria had a limited translation mechanism suggesting its strong dependence to its hosts. However, the clear-cut distinction between mutualism and parasitism of the wChem in C. hemipterus cannot be yet ruled out.
\end{abstract}

Keywords: Wolbachia; bedbug; Cimex hemipterus; isolation; culture; genomics; B-vitamins 


\section{Introduction}

Bacteria of the genus Wolbachia represent the most successful symbiotic bacteria in the terrestrial ecosystem. Gram-negative bacteria of the family Anaplasmataceae in the order Rickettsiales, they are obligatory intracellular endosymbionts of several invertebrate taxa, Arthropoda and Nematoda. Till now, only one species, Wolbachia pipientis, has been axenically isolated and officially described [1]. Wolbachia are genetically diverse, as are the interactions with their hosts [2-6]. Most of Wolbachia genotypes, representing microbiologically separate species, were never isolated in pure culture. Currently, there is a general consensus to classify all genotypes in monophyletic lineage groups or supergroups from A to $\mathrm{R}$, with a new supergroup " $\mathrm{S}$ " recently identified from the pseudoscorpion Atemnus politus [7]. The supergroups C, D and J infect exclusively filarial nematodes (Onchocercidae) [8-10]. Supergroup L exclusively contains plant parasitic nematodes (Pratylenchidae) [11,12]. Wolbachia supergroup F is the only clade composed by strains that infecting arthropods and some infecting filarial nematodes $[13,14]$. This includes especially hematophagous arthropods, such as biting Diptera and Hemiptera, fleas, lice and parasitic mites [15-26]. Recently, a novel strain of Wolbachia belonging to the supergroup F was isolated in Ixodes scapularis cells from a pool of Ctenocephalides sp. cat fleas [3].

The problems in Wolbachia taxonomy are evident. Different Wolbachia genotypes correspond clearly to different species both genetically and biologically [27]. Genetic distances among Wolbachia supergroups are huge, moreover, the same genotype may infect different insect species. Although attempts to classify Wolbachia in different genera were already done [28], but not widely accepted, mostly because of the difficulties in strain isolation [29]. Until recently, only few Wolbachia strains from clades A and B were known in axenic culture. The recent isolation of Wolbachia from Ctenocephalides felis in tick cell line is a rare example of a successful isolation of Wolbachia strain in cell culture [3].

Five distinct reproductive manipulations are induced in Wolbachia arthropod hosts: cytoplasmic incompatibility (CI), parthenogenesis induction, killing of male, feminization and meiotic drive, all of which promote its spread by reducing competition for resources from males (a dead-end host) or by imposing an adaptation cost on uninfected females [30-33]. In some cases, Wolbachia form obligate and apparently beneficial relationships with their hosts [34,35]. For blood-feeding Diptera, the CI is the common phenotype $[3,17,22]$. In addition, Wolbachia has long been of applied interest in biological control for vector-borne disease control, Wolbachia symbiosis can be harnessed for vector control as well as the potential to combine the sterile insect technique and Wolbachia-based approaches for the enhancement of population suppression programs [36]. In filarial nematode diseases such as onchocerciasis and lymphatic filariasis, the use of antibiotics for Wolbachia elimination can safely clear adult worm infections [37]. Furthermore, several control programs releasing Wolbachia-infected Aedes aegypti to reduce the transmission of dengue and other arboviruses [38], because of Wolbachia infections can suppress the dissemination and transmission of pathogens in insects, especially when transinfected into a novel host [39].

Bed bugs are obligatory hematophagous insects with hemimetabolous development from egg to adult through five nymphal stages (instars), each of which requires a blood-meal to molt to the next stage [40]. They have re-emerged over the last decades worldwide where they may cause problems in housing facilities, public facilities, and residential complexes. In economically advanced countries, they are a serious public health. Bed bug infestations have been reported to have physical and psychological effects in humans. In addition, despite isolation of several pathogens, found in the bed bug body, they have not been confirmed as a vector of pathogens to humans [41,42].

Infections with Wolbachia species of F supergroup seem to be common in the Cimicinae subfamily (Cimex and Oeciacus genera) [40,42]. Wolbachia's relationship with Cimex lectularius presumably evolved from a facultative association to obligate mutualism where the bacteria garner protection and nutrients within their host in exchange for supplementing the host's nutritional needs [20,22,43]. It was suggested 
new hypotheses about the coordination of Wolbachia growth and regression with its host's physiology and endocrine events [40].

Here, on the basis of taxono-genomic approach, we present the description of Wolbachia massiliensis strain PL13 (CSURP2929), a new species of the genus Wolbachia belonging to a new Supergroup T, isolated from wild bed bugs Cimex hemipterus from Senegal. Its growth condition as well as complete annotated genome are detailed.

\section{Results}

\subsection{Isolation, Culture, and Description of the Bacterium}

Four of ten inoculated shell vials produced morphologically identical bacterial strains. Intracellular growth of bacteria were observed beginning from 14th day post inoculation. The $16 \mathrm{~S}$ rRNA sequencing revealed the homogeneity of all isolated strains which belonged to the genus Wolbachia according to the blast analysis. One strain, designated Wolbachia sp. wChem PL13, was then selected for the following investigations and characterization. wChem PL13 was best visualized by the Diff-Quick staining while on the Gimenez and Gram staining the bacteria stained poorly, but always appeared to be gram negative. The bacteria appeared as small cocci not connected with each other inside intracellular vacuoles but not in the cytoplasm nor in the nucleus (Figure 1a). Therefore, the infected cells showed several vacuoles of different size according to the bacterial load within these latter (Figure 1a). Heavy infected cells were often disrupted during centrifugation using a Cytospin (Thermo Shandon) centrifuge as revealed by subsequent staining suggesting the fragility and death of S2 cells at hight infection levels (Figure 1b). Meanwhile, the infected cells continued to be able to multiply without there being any obvious cytopathic effect. Scanning microscopic examination showed that the bacterium present in the extracellular environment following cell lysis during cytocentrifugation have an average dimension of $570 \mathrm{~nm}$ (range: 530 to $615 \mathrm{~nm}$ ). The bacteria present a regular form of a small cocci (Figure 1c).

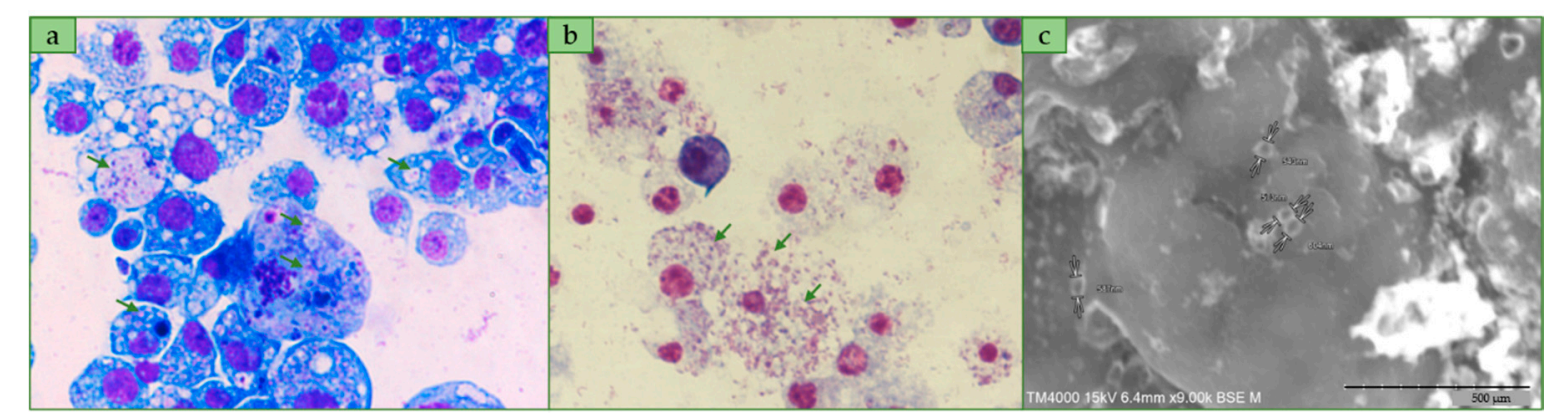

Figure 1. wChem PL13 grown (arrowed) in S2 cell-line. (a,b): Diff-Quik staining, $\times 1500$ showing the intravacuolar location and bacterial load of the wChem PL13 strain, respectively. (c): scanning microscopic examination of the $w$ Chem PL13 strain.

The strain $w$ Chem PL13 was successfully propagated throughout both S2 and C6/36 cell lines. The bacterial growth was better within $\mathrm{S} 2$ cell lines at $28^{\circ} \mathrm{C}$ according to the qPCR results (Table S1). The difference between S2 and C6/36 cell lines in terms of bacterial load has become significant after three weeks of co-culture, while the difference between culture conditions (temperatures) has become significant after two weeks favorably to cultures maintained at $28^{\circ} \mathrm{C}$ for both cell lines (Table S1). In term of speed of growth, the load of the $w$ Chem PL13 strain has become significantly observable after two and three weeks of co-culture with S2 cells maintained at $28^{\circ} \mathrm{C}$ and room temperature respectively, and after three weeks within $\mathrm{C} 6 / 36$ cells from both conditions $\left(28^{\circ} \mathrm{C}\right.$ and room temperature) (Table S1).

During the whole processes of the purification, no loss of the bacterium and the sonication step induced only the lysis of cells but not that of the bacteria (Figure S1a), while the gradient density purification provided an integrated bacterium with high density concentration (Figure S1b). 
Accordingly, the qPCR results indicated the maintenance of bacterial load during all purification steps. At the end of the purification, the bacteria were highly concentrated which gave the $\mathrm{Ct}$ value of 11.23 corresponding to $42.86 \mathrm{ng} / \mu \mathrm{L}$.

\subsection{Genome Sequencing, Annotation and Genomic Comparison}

De novo assembly based on Illumina and MinION rids (Figure S2) gave a genome sequence from the $w$ Chem PL13 constructed by one contig of 1,291,339 with a G + C content of 35.4\% (Figure 2a). We identified a total of 1226 predicted protein-coding genes, in addition to 3 complete rRNA operons, 32 tRNAs and 1 tmRNA. Comparison of these genomic data with those from of the other Wolbachia supergroups showed that the genome of wChem PL13 is close to those encountered in other insects (Table 1). The strain wChem PL13 showed the presence of two prophage regions of $14.5 \mathrm{Kbp}$ and $23.4 \mathrm{Kbp}$ (Figure 2a and Figure S3). Blast analysis revealed that the wChem PL13 prophages shared up to 19\% to $58 \%$ with an identity ranged from $76.76 \%$ to $87.25 \%$ with those of other insect-associated Wolbachia such as wDmel, Wolbachia of D. melanogaster from supergroup A (AE017196) and wFcan, Wolbachia of F. candida from supergroup E (CP015510). However, up to 50\% of the predicted protein-coding genes from the PL13 genome were shared with other Wolbachia supergroups (Figure 2b).

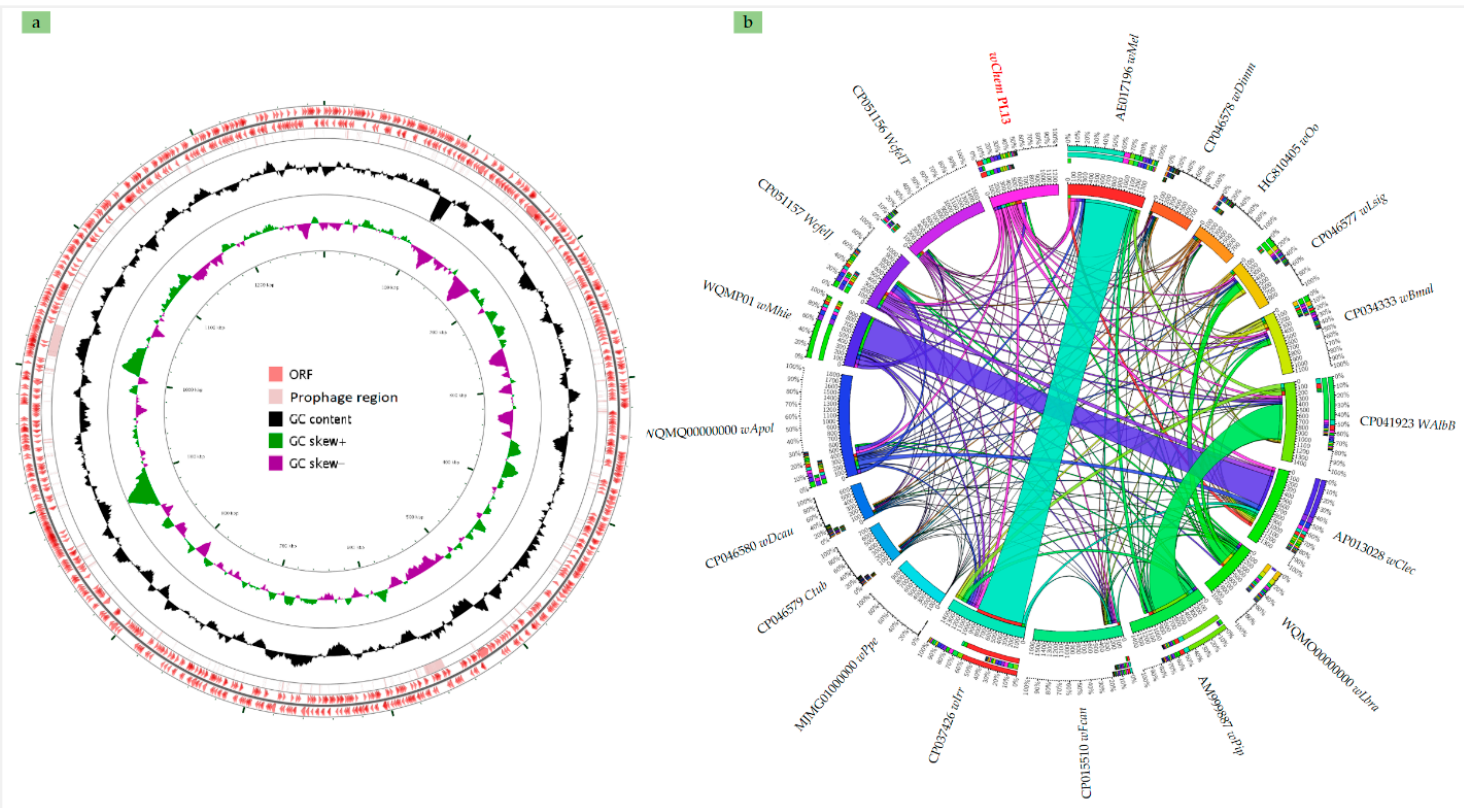

Figure 2. The complete chromosome of the Wolbachia sp. wChem PL13. (a): circular map showing the annotation of the whole genome. (b): rhizome showing gene sharing between Wolbachia genomes.

Ortho-ANI values (Figure 3a) ranged from 74.63\% with wPpe, Wolbachia supergroup L from P. penetrans (MJMG01000000) to $84.82 \%$ with wClec, Wolbachia supergroup F from C. lectularius (AP013028). The pangenome analysis of the wChem PL13 strain showed a total of 11,402 clusters genes distributed as follows: (Core genes $=0$ ), (Soft core genes $=0$ ), (Shell genes $=210$ ) and (Cloud genes $=11,192)$, respectively. The Ortho-ANI and the pangenome trees were clearly congruent (Figure 3a,b), where the wChem PL13 strain clustered with wApolK5, Wolbachia supergroup S from A. politus (WQMQ00000000), wClec, Wolbachia supergroup F from C. lectularius (AP013028) and wCfeJ, an undescribed Wolbachia supergroup from C. felis (CP051157).

Genomic comparison of the wChem PL13 strain with the other Wolbachia supergroups using Digital DNA-DNA hybridization values (dDDH) are reported in Table 2. For the strain PL13, these values ranged from $19.8 \%$ with Ctub, Wolbachia supergroup J from C. tuberocauda (CP046579) to 30\% with wApolK5, Wolbachia supergroup S from A. politus (WQMQ00000000). 
Table 1. General features of wChem PL13 and other Wolbachia genomes.

\begin{tabular}{|c|c|c|c|c|c|c|c|c|c|c|}
\hline Strain Information & wChem PL13 & wClec & wDmel & wPip & wFcan & wApol & $w C f e J$ & $w B m a l$ & wDimm & wPpe \\
\hline Host type & \multicolumn{6}{|c|}{ Insects } & \multicolumn{4}{|c|}{ Nematodes } \\
\hline Wolbachia host & C. hemipterus & C. lectularius & D. melanogaster & C. quinquefasciatus & F. candida & A. politus & C. felis & B. malayi & D. immitis & P. penetrans \\
\hline Supergroup & New supergroup " $\mathrm{T}$ " & $\mathrm{F}$ & A & B & $\mathrm{E}$ & S & Undescribed & $\mathrm{D}$ & C & $\mathrm{L}$ \\
\hline \multicolumn{11}{|l|}{ Genome features } \\
\hline Accession Number & СР061738 & AP013028 & AE017196 & AM999887 & СР015510 & WQMQ00000000 & СР051157 & СР034333 & СР046578 & MJMG01000000 \\
\hline Total length (bp) & $1,291,339$ & $1,250,060$ & $1,267,782$ & $1,482,455$ & $1,801,626$ & $1,445,964$ & $1,201,647$ & $1,080,064$ & 920,122 & 975,127 \\
\hline No. of contigs & 1 & 1 & 1 & 1 & 1 & 373 & 1 & 1 & 1 & 12 \\
\hline GC content $(\%)$ & 35.4 & 36.3 & 35.2 & 34.2 & 34.4 & 35.6 & 35.6 & 34.2 & 32.7 & 32.2 \\
\hline N50 & $1,291,339$ & $1,250,060$ & $1,267,782$ & $1,482,455$ & $1,801,626$ & 5741 & $1,201,647$ & $1,080,064$ & 920,122 & 9,555 \\
\hline Gap ratio (\%) & 0.326793 & 0.0 & 0.0 & 0.006746 & 0.0 & 0.0 & 0.0 & 0.0 & 0.0 & 0.13547 \\
\hline No. of CDSs & 1194 & 1226 & 1211 & 1395 & 1591 & 1546 & 1045 & 1017 & 709 & 939 \\
\hline No. of rRNA & 3 & 3 & 3 & 3 & 3 & 3 & 3 & 3 & 3 & 3 \\
\hline No. of tRNA & 32 & 34 & 34 & 34 & 35 & 39 & 34 & 34 & 34 & 35 \\
\hline No. of CRISPRS & 0 & 0 & 0 & 0 & 0 & 0 & 0 & 0 & 0 & 0 \\
\hline Coding ratio (\%) & 78.5 & 77.3 & 81.6 & 84.4 & 86.9 & 66.1 & 82.3 & 70.1 & 70.7 & 84.8 \\
\hline Completeness (\%) & 98.00 & 98.00 & 98.73 & 99.45 & 97.27 & 95.89 & 98.36 & 99.09 & 98.00 & 93.32 \\
\hline Contamination (\%) & 0.36 & 0.36 & 0.00 & 0.00 & 1.55 & 19.67 & 0.36 & 0.00 & 0.00 & 2.73 \\
\hline No. of prophage & 2 & 3 & 3 & 4 & 6 & 2 & 0 & 0 & 0 & 1 \\
\hline
\end{tabular}

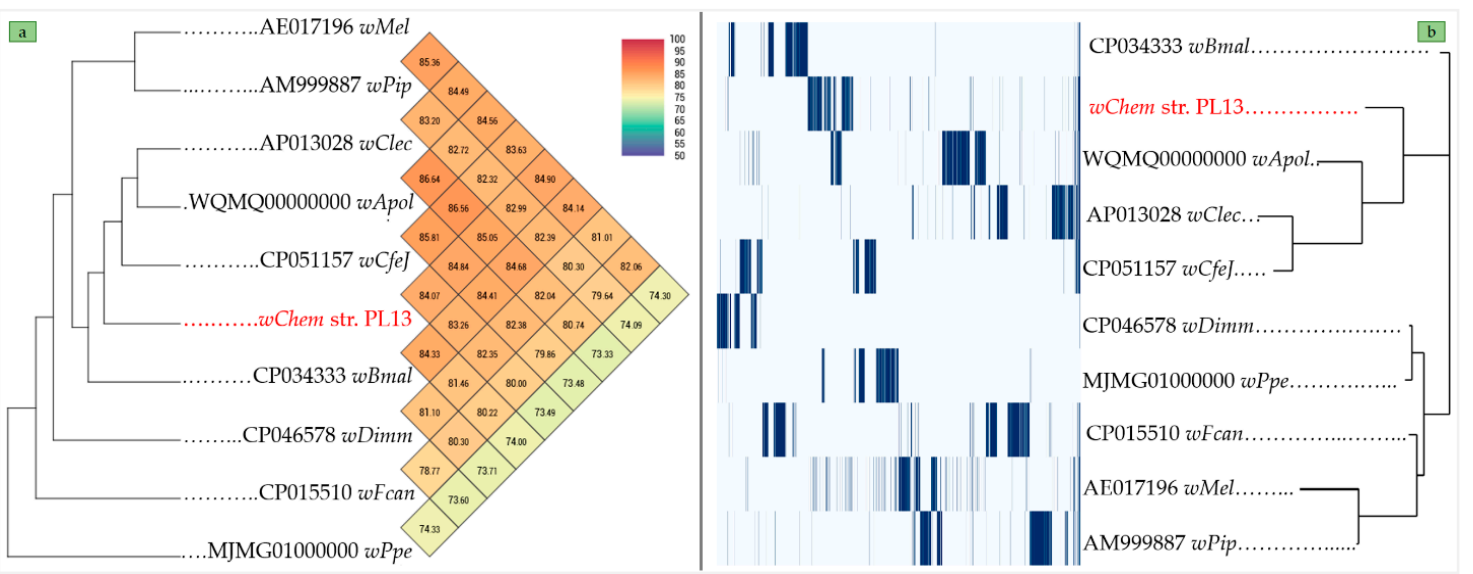

Figure 3. (a). heatmap generated with Ortho-ANI values between the wChem PL13 strain and the other Wolbachia supergroups. (b). pan-genome analysis of $w$ Chem PL13 strain based on the maximum likelihood tree from the accessory genome elements (right). The presence (blue) and absence (white) of accessory genome elements are presented on the left matrix. 
Table 2. dDDH values of the wChem PL13 comparatively to the other Wolbachia supergroups.

\begin{tabular}{cccccccc}
\hline Strain & Wolbachia Host & $\begin{array}{c}\text { Accession } \\
\text { Number }\end{array}$ & DDH & Distance & Prob. DDH $\geq \mathbf{7 0} \%$ & $\begin{array}{c}\text { G + C } \\
\text { Difference }\end{array}$ & Model C.I. \\
\hline wPpe & P. penetrans & MJMG01000000 & 19.8 & 0.2216 & 0 & 3.21 & {$[17.6-22.2 \%]$} \\
Ctub & C. tuberocauda & CP046579 & 23 & 0.1901 & 0 & 3.09 & {$[20.7-25.5 \%]$} \\
WCfelT & C. felis & CP051156 & 23.6 & 0.1853 & 0 & 0.19 & {$[21.3-26 \%]$} \\
wFcan & F. candida & CP015510 & 24.1 & 0.1809 & 0.01 & 1.02 & {$[21.8-26.6 \%]$} \\
wDimm & D. immitis & CP046578 & 24.8 & 0.1757 & 0.01 & 2.67 & {$[22.5-27.3 \%]$} \\
wCmeg & C. megacephala & CP021120 & 27 & 0.1599 & 0.03 & 1.42 & {$[24.7-29.5 \%]$} \\
wDit & D. citri & CP051608 & 27 & 0.1604 & 0.03 & 1.38 & {$[24.6-29.4 \%]$} \\
wPip & C. quinquefasciatus & AM999887 & 27.1 & 0.1598 & 0.03 & 1.18 & {$[24.7-29.5 \%]$} \\
wCfeJ & C. felis & CP051157 & 27.8 & 0.155 & 0.04 & 0.2 & {$[25.4-30.3 \%]$} \\
wBmal & B. malayi & CP034333 & 28.4 & 0.1512 & 0.05 & 1.19 & {$[26-30.9 \%]$} \\
wDmel & D. melanogaster & AE017196 & 29.3 & 0.1462 & 0.08 & 0.14 & {$[26.9-31.8 \%]$} \\
wClec & C. lectularius & AP013028 & 29.3 & 0.1462 & 0.08 & 0.88 & {$[26.9-31.8 \%]$} \\
wApolK5 & A. politus & WQMQ00000000 & 30 & 0.1423 & 0.1 & 0.23 & {$[27.6-32.5 \%]$} \\
\hline
\end{tabular}

\subsection{B-Vitamin Synthesis Patterns in the wChem PL13 and Other Wolbachia Genomes}

The inspection of $w$ Chem PL13 genome revealed B-vitamins synthetic pathways commonly present in the most Wolbachia genomes. This include the complete pathway for riboflavin (vitamin B2) and for folate (vitamin B9) with a partial pathway for both pyridoxine (vitamin B6) and thiamine (vitamin B1). Unlike Wolbachia of C. lectularius, the biotin (vitamin B7) biosynthesis pathway was completely absent in the genome of the wChem PL13 strain (Figure 4a).

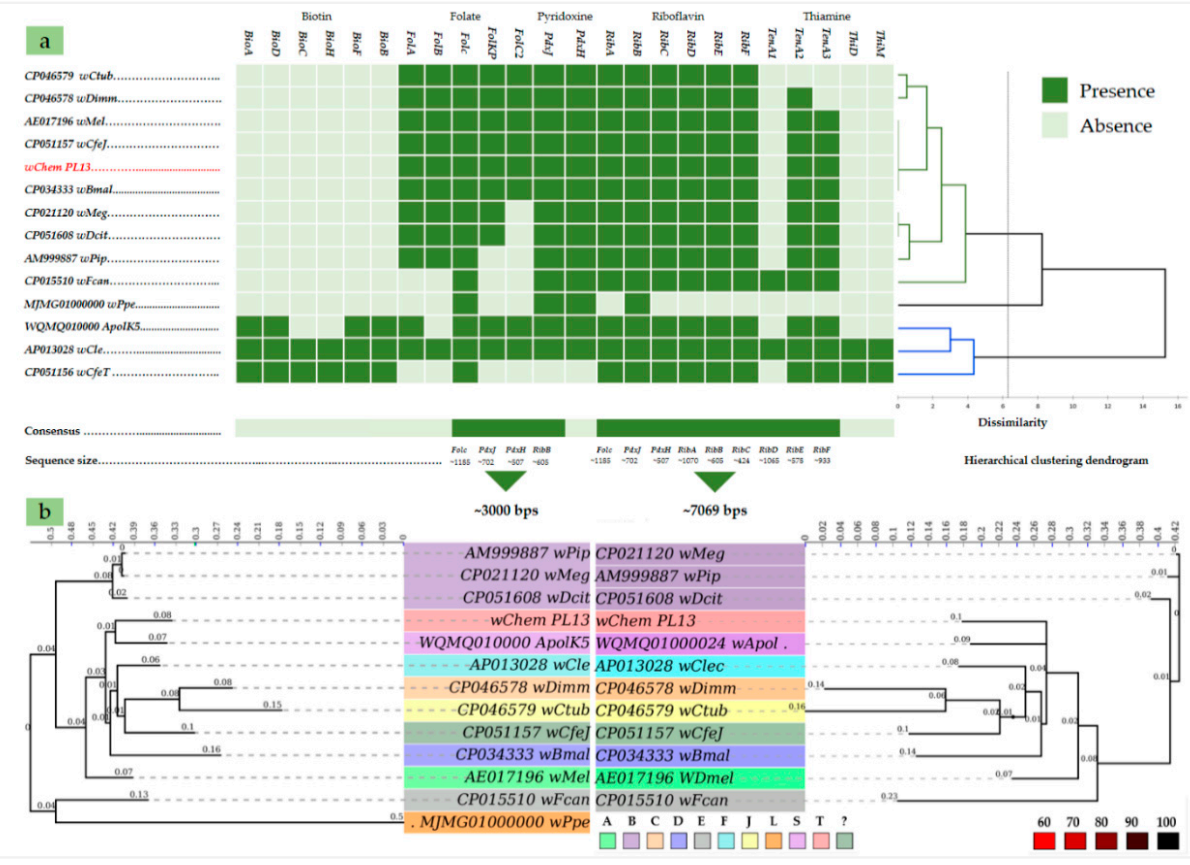

Figure 4. (a). Comparative analysis of B-vitamins biosynthesis pathways of the wChem PL13 strain and the other Wolbachia strains. a. Matrix based on the presence/absence of B-vitamins biosynthesis genes from the wChem PL13 and the other Wolbachia strains. The matrix was organized according to the hierarchical clustering (AHC) of B-vitamins profile among Wolbachia strains (left cladogram). (b). Maximum likelihood phylogenies based on $3000 \mathrm{bps}$ (right phylogram) and $7069 \mathrm{bps}$ (left phylogram) using respectively K81uf $(+G)[44]$ and GTR $(+G)[45]$ substitution models. Likelihoods values were -16949.78 and -36573.10 respectively. Values above branches indicate the length of each branch's, while the axis showed the global distance observed throughout the trees. Color codes indicating the Wolbachia supergroup (label) and the bootstraps percent's (branches).

Both datasets based on gene involved in B-vitamins biosynthesis produced a close topology and very similar posterior bootstrap values. Insect-associated Wolbachia from the A, B and E supergroups 
as well as the supergroup L from the non-filarial nematode had an earliest divergence compared to the filarial and the other insect-associated Wolbachia. However, the wChem PL13 strain and the supergroup $\mathrm{T}$ appeared to be a monophyletic sister with the clade regrouping the supergroup $\mathrm{F}$ from C. lectelarius and C, D and J supergroups from filarial nematodes (Figure $4 \mathrm{~b}$ ), suggesting a less older B-vitamins biosynthesis genes compared to those from the other insect-associated Wolbachia (e.g., A, $B$ and E supergroups).

\subsection{Comparative Phylogenies and Placement of Wolbachia sp. Strain wChem PL13 in the Wolbachia T Supergroup}

Together, the SLST based on the $16 \mathrm{~S}$ and the WSP genes, the MLST based on the ten selected genes (16S, 23S, GroL, rpoB, gatB, coxA, dnaA, fbpA, puuA and nusA) as well as the genome-based phylogeny allowed the comparison of the $w$ Chem PL13 strain with all known Wolbachia supergroups except for G, $\mathrm{Q}$ and $\mathrm{P}$ supergroups, where the suitable dataset were not available. However, the blast comparison of the 16S gene from the wChem PL13 strain with Wolbachia of Diaea sp. (AY486069) supergroup G [46], Wolbachia of Torotrogla cardueli (KP114100) supergroup Q and Wolbachia of Torotrogla merulae (KP114099) supergroup P [47], revealed an identity-query cover of $97.77-53 \%, 97.72-41 \%$ and $98.54-41 \%$ respectively, which is lower than the $98.7 \%$ threshold used to discriminate bacterial species [48].

All cladograms constructed from the SLSTs (Figure S4a,b), MLST (Figure 5a) and genome-based phylogeny (Figure 5b) supported the divergence of the wChem PL13 strain from known Wolbachia supergroups. Notably, both MLST and genome-based phylogenies produced similar topologies within the same clade and very similar bootstrap values. The only topology differences between trees based on MLST and the Wolbachia whole genome datasets were the varying positions of $w C f e J$, an undescribed Wolbachia supergroup from C. felis (CP051157) and wApolK5, Wolbachia supergroup S from A. politus (WQMQ00000000), but otherwise no conflicts in Wolbachia clade topologies were observed (Figure 5a,b).
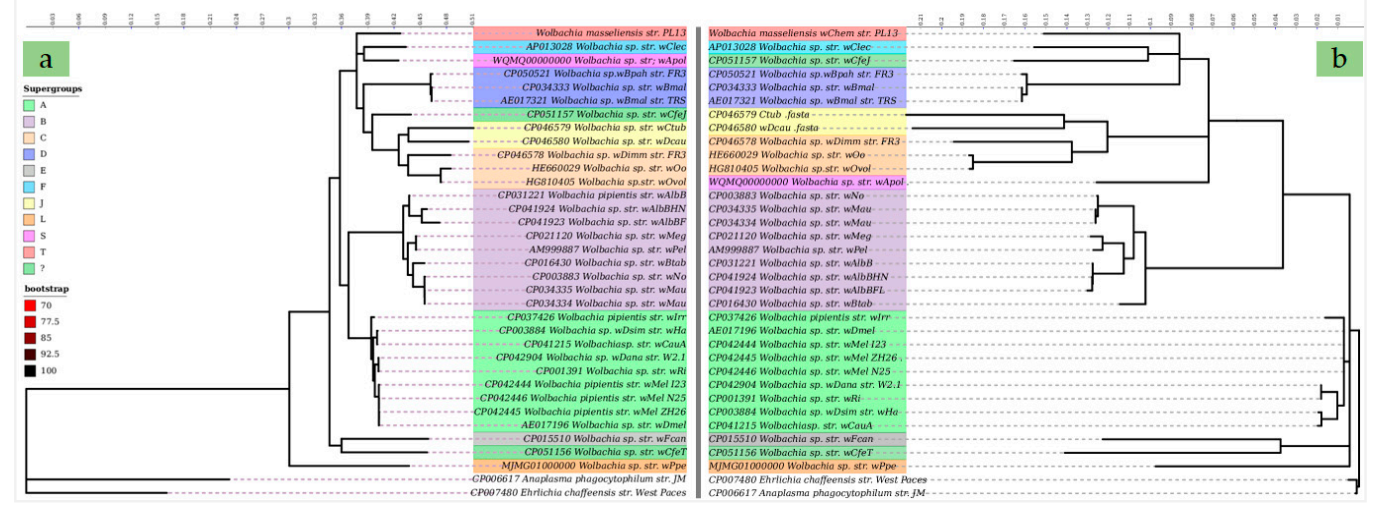

Figure 5. Comparative phylogenies showing the position of the $w$ Chem PL13 strain among the other Wolbachia supergroups. (a). IQTREE based on ML method with 1000 bootstraps from the concatenated ten selected genes using GTR $(+\mathrm{F}+\mathrm{R} 3)$ substitution model [49]. Outgroup taxons "Ehrlichia chaffeensis (CP007480) and Anaplasma phagocytophilum (CP006617)" are drawn at root. Log-likelihood of consensus tree is -88934.819989 . (b). Genome based phylogeny generated using the FastTree Version 2.1.10, double precision (No SSE3) [50]. The tree was rooted using Jukes-Cantor Joins model with 1000 local boots. The nearest-neighbor interchange (NNI) and the subtree pruning and regrafting (SPR) (2 rounds range 10) were used for the tree rearrangement. The Top Hits was 1.00 * sqrtN.

\subsection{Description of Wolbachia massiliensis sp. nov.}

From all descriptive results taken together, the wChem-PL13 isolated from the bedbug C. hemipterus strain constitutes a divergent Wolbachia strain. Genotypic profile based on the 16S and the WSP phylogenies, the MLST combining the $16 \mathrm{~S}$ and $23 \mathrm{~S}$ rRNA, rpoB, GroL, CoxA, DnaA, fbpA, Asn/Gln, gatB, NusA and PuuA and the genome-based phylogeny as well as the taxo-genomic features delineated 
a distinct species, clearly different from all other recognized Wolbachia strains. We propose the name Wolbachia masseliensis sp. nov. designated wChem-PL13 strain.

Wolbachia masseliensis (mas.si' li.en.sis. L. gen. adj. massiliensis, from Massilia, the Latin name of Marseille, France, where the organism was first grown, identified and characterized). Since the current Wolbachia supergroup classification system is yet be revisited [29], we maintain the notion of supergroup at a strain level and we propose a new supergroup T with a type strain Wolbachia masseliensis sp. nov. strain wChem-PL13. The known host of this bacterium is Cimex hemipterus, a wild strain from Senegal. This isolate has been deposited in the strain collection CSUR (Collection de Souches de l'Unité des Rickettsies WDCM 875) under the accession number CSURP2929. The complete genome sequence of W. masseliensis is available in GenBank: Bio Project PRJNA663644; Bio Sample: SAMN16175503 and genome accession number CP061738.

The cells are best visualized by the Diff-Quick staining and appear to be gram negative, small isolated cocci with an average dimension of $570 \mathrm{~nm}$ (range: 530 to $615 \mathrm{~nm}$ ). The bacteria are obligate intracellular and occur inside vacuoles of eukaryotic cells (A. albopictus and D. melanogaster). The bacteria grow in S2-cell line at $28^{\circ} \mathrm{C}$ in Schneider medium supplemented with $10 \%$ of decomplemented Bovine Serum Albumin (BSA) and $1 \%$ of the combination Penicillin/Streptomycin antibiotics.

\section{Discussion}

In the present study we demonstrate the possibility to use S2 cells for the isolation and maintenance of Wolbachia. Our data demonstrated the susceptibility of two arthropod cells derived from D. melanogaster and A. albopictus mosquito, arthropods naturally infected with well-known Wolbachia supergroup A and B, respectively. However, the best bacterial growth was obtained after two weeks on Drosophila S2 cell lines. Several cell lines were previously used in the isolation and/or cultivation of Wolbachia bacterium including the Aa23 mosquito cell line [51,52], C6/36 cells, another A. albopictus cell line and the human embryonic lung (HEL) fibroblast monolayers [52] for wALB13, Wolbachia supergroup B from A. albopictus. Different cell lines derived from Ixodes scapularis and I. Ricinus as well as well as the A. albopictus cells (AeAl-2) were used for the propagation of three Wolbachia strains $w$ Stri, supergroup $\mathrm{A}, w A l b B$ supergroup $\mathrm{B}$ and $w C f e F$ supergroup $\mathrm{F}$ from Laodelphax striatellus, A. albopictus and C. felis, respectively [3].

Despite the successful propagation of different Wolbachia supergroups on different mammalian and insects cell lines, there are no standardized cell line for the co-culture of Wolbachia. Our data showed that the infection of up to $97 \%$ S2 cells with Wolbachia from C. hemipterus occurred at 11 days which consist with the results previously obtained on Aa23 mosquito cells, naturally found infected with Wolbachia [51]. Since the ability of the S2 cell line to provide a similar Wolbachia growth to that obtained on naturally infected cell line, we propose S2 cell line as standard line for Wolbachia culture.

It is clear from our results that culture temperature affects the growth of Wolbachia, where the best growth was always at $28{ }^{\circ} \mathrm{C}$, the adequate temperature for $\mathrm{S} 2$ and $\mathrm{C} 6 / 36$ cell lines. However, several studies shown that the in vivo growth of Wolbachia was always in line with the culture temperature of the cell line which varied from $28^{\circ} \mathrm{C}$ to $37^{\circ} \mathrm{C}[3,51,52]$.

Recently, it was demonstrated that changes to host temperature preference do not alter bacterial load of several A and B-supergroup Wolbachia strains. However, hosts infected with A-group Wolbachia strains prefer cooler temperatures while those infected with B-group Wolbachia strains prefer a warmer temperature, suggesting that Wolbachia strains are differently involved in the host-thermoregulation [53].

Recently, an efficient genome sequencing approach based on probe hybridization enrichment was developed to provide Wolbachia genomes directly from their hosts [54]. However, the application of the approach was strongly limited by the amount of bacteria from their hosts, as it was the cases of wApolK5, Wolbachia supergroup S from A. politus (WQMQ00000000) and wLbra, Wolbachia supergroup D from Litomosoides brasiliensis (WQMO00000000) [7,55]. In addition to the manipulation of the bacterium, 
the standardized protocol for the isolation, culture as well as the purification of Wolbachia herein we described, leading to easily obtain enough bacterial DNA which facilitate the genome sequencing.

We obtained the complete genome of wChem PL13 strain, W. massiliensis, a type strain of new supergroup $\mathrm{T}$ from $C$. hemipterus $(1,250,060 \mathrm{bp}$ long) which closely mimic the size of $w$ Cle, Wolbachia supergroup F from C. lectelarius $(1,291,339)$ and wDmel, Wolbachia supergroup A from D. melanogaster $(1,267,782)$ genomes. However, it seems to be the smaller complete genome from insect-associated Wolbachia since the size of complete insect-associated Wolbachia genomes ranged between 1, 133,809 bp long and 1,801,626 bp long [6,56]. While it was clearly bigger than those associated to nematodes where the size ranged from 920,122 bp long to 1,080,064 bp long [55,57]. Furthermore, we noted the presence of two sequences coding for phage-like proteins, such as portal, coat transposons, and integrase proteins (Figure S3). Wolbachia phage-like proteins were mostly identified in insect-associated Wolbachia and in wPpe, Wolbachia supergroup L from plant parasitic nematode (MJMG01000000), while they were completely absent in filarial-associated Wolbachia (Table 1) suggesting Wolbachia bacteriophage (WO) infections from the environment of their hosts. Furthermore, the molecular analysis of the prophage coding sequences from W. massiliensis wChem PL13, revealed a partial similarity with those encountered in wDmel, Wolbachia of D. melanogaster from supergroup A (AE017196) and wFcan, Wolbachia of F. candida from supergroup E (CP015510). Wolbachia-bacteriophage WO relationship was molecularly studied in wasps community [58]. Authors were noted the absence of congruence between WO and host Wolbachia as well as WO and insect host, suggesting that the phage WO exchanged frequently and independently within the closed syconium [58].

The genome of W. massiliensis, wChem PL13 strain from the bedbug C. hemipterus revealed similar metabolic capacities among the parasitic insect-associated Wolbachia from A and B-supergroups. By contrast, the mutualistic bedbug-Wolbachia supergroup F from C. lectularius [59] closed to the other mutualistic Wolbachia supergroups [57] (Figure 4). This emphasis the diversity of Wolbachia-host relationship among the bedbugs. Except for the translation COG category [J] which appears to be reduced in the genome of $W$. massiliensis suggesting a strong dependence to its host. Though the lack of information about the distribution of Wolbachia as well as their relationship within C. hemipterus hosts, which may represent a limitation of our study, the clear-cut distinction between mutualism and parasitism cannot yet be ruled out. Although it is difficult to conclude about the provision of nutritional elements to the host by $W$. massiliensis as long as the biotin pathway was completely absent. The biotin appears to be rare among Wolbachia supergroups and was detected only in few insect-associated Wolbachia [7]. The complete Wolbachia biosynthesis pathway for the biotin was firstly detected in the bedbug Wolbachia of C. lectularius wClec. In addition to the biotin, $w$ Clec participates in the host fitness by producing B-vitamins $[59,60]$. The biotin was latter well studied in the community of Cimex and Paracimex arthropods using gene-specific PCRs [60]. Authors reported the functional biotin pathways in at least 10 out of 15 studied genera but not in C. hemipterus [60]. The absence of Wolbachia-biotin production in the bedbug C. hemipterius could be compensated by the other symbiotic bacterium. The genetic study of the origin of biotin operons demonstrated that they were acquired via lateral gene transfer presumably from a coinfecting endosymbiont Cardinium or Rickettsia [59]. The congruence between the phylogenies of B-vitamins operons (i.e., riboflavin, folate and pyridoxine) consistently exhibited similar evolutionary patterns with Wolbachia phylogeny. Consequently, it is conceivable, although speculative, B-vitamins synthesis genes are originated from the other symbiotic bacterium within their hosts as it was the case of biotin and thiamine from the bedbug-Wolbachia of C. lectelarius and the obligate symbiont Wigglesworthia glossinidia of tsetse flies [59,61].

\section{Materials and Methods}

\subsection{Source of the Bacterium, Inoculum Preparation and Isolation}

The bacterial strain was isolated from wild Cimex hemipterus (Fabricius, 1803) collected in Dakar, Senegal (2017). Ten adult bed bugs were morphologically identified on the basis of the following 
criteria: width/length ratio of the pronotum less than 2, lateral lobes of the pronotum are narrow and hind margins of hemelytral pads are broadly rounded on the inner halves. Once identified, the adult specimens were individually used to isolate the intracellular bacterium using cell co-culture method using the Schneider 2 cell-line (S2) primarily derived from a culture of the late stage (20-24 h old) Drosophila melanogaster embryos [62]. This cell line has previously proven to be receptive for several Rickettsiales bacterium such as Rickettsia assemboensis and Rickettsia felis [63,64]. Briefly, adult bugs Cimex hemipterus were rigorously decontaminated by immersing adult bedbug during $5 \mathrm{~min}$ into $1 \%$ of Sodium Hypochlorite solution (Sigma Aldrich, Saint-Quentin-Fallavier, France) followed by rinsing in sterile water and immersing into $70 \%$ ethanol and sterile water rinsing again. Each specimen was manually crashed in $1 \mathrm{~mL}$ of Schneider medium (Sigma Aldrich, Saint-Quentin-Fallavier, France) to generate the bacterial inoculum. Wolbachia cell co-culture was inoculated in the shell vial tubes containing $1 \mathrm{~mL}$ of S2 culture as described elsewhere $[65,66]$. Culture media consisted of a Schneider medium supplemented with 10\% of decomplemented Bovine Serum Albumin (BSA) (Sigma Aldrich, Saint-Quentin-Fallavier, France) and 1\% of the combination Penicillin/Streptomycin (Sigma Aldrich, Saint-Quentin-Fallavier, France) antibiotics to avoid ubiquitous bacterial contamination. The mixture was sterilized using $0.2 \mu \mathrm{m}$ filtration and was then kept at $4{ }^{\circ} \mathrm{C}$ until use. The infection was performed using $200 \mu \mathrm{L}$ of the bacterial inoculum derived from adult $\mathrm{C}$. hemipterus. One hour of centrifugation at $4000 \mathrm{rpm}$ at $28^{\circ} \mathrm{C}$ was performed to increase Wolbachia-cell adhesion. Shell vials of infected cultures were kept at $28^{\circ} \mathrm{C}$. Isolation success was assessed using Diff-Quick ${ }^{\mathrm{TM}}$ staining (Dade Behring, Marburg, Germany) each 7 days followed by sequencing of the 16S RNA gene [67]. During the isolation period, the maintenance of cell culture was performed by a partial renewal of culture medium each 7 days. Shell vials were centrifuged at $3000 \mathrm{rpm}$ at $28^{\circ} \mathrm{C}$, then a half of the supernatant $(500 \mu \mathrm{L})$ was replaced by a fresh medium under sterile conditions.

\subsection{Morphological Characterization and Scanning Electron Microscopy}

Infected cells were cytocentrifuged for staining with Gimenez and Diff-Quick (Dade Behring, Marburg, Germany) and were then examined under light microscope Leica ${ }^{\circledR}$ DM LB2.

For the electron microscopy, $200 \mu \mathrm{L}$ of 11 old days PL13-S2 co-culture were centrifuged for $15 \mathrm{~min}$ at $3000 \mathrm{rpm}$, then the supernatant was removed, and the pellet was fixed using $2.5 \%$ glutaraldehyde (Sigma Aldrich, Saint-Quentin-Fallavier, France) in $0.1 \mathrm{M}$ sodium cacodylate buffer (Sigma Aldrich, Saint-Quentin-Fallavier, France) for $1 \mathrm{~h}$. After fixation, the pellet was rinsed three times with $0.1 \mathrm{M}$ sodium cacodylate ( $5 \mathrm{~min}$ each) to remove residual fixative. The graded ethanol concentrations ( $25 \%$ for $5 \mathrm{~min}$; $50 \%$ for $5 \mathrm{~min} ; 70 \%$ for $5 \mathrm{~min}$; $85 \%$ for $5 \mathrm{~min}$; $95 \%$ for $5 \mathrm{~min}$ (twice); $100 \%$ ethanol for $10 \mathrm{~min}$ (three times) was used for sample dehydration. Finally, the pellet was incubated for $5 \mathrm{~min}$ in an ethanol/Hexamethyldisilazane (Sigma Aldrich, Saint-Quentin-Fallavier, France) (1:2) mixture, then in pure HMDS. The mixture was cytocentrifuged for $5 \mathrm{~min}$ at $2000 \mathrm{rpm}$ and the glass slide allowed to air dry for 30 min before observation. The examination was performed using a TM4000 Plus ${ }^{\mathrm{TM}}$ (Hitachi, Tokyo, Japan) scanning electron microscope operated at $10 \mathrm{kV}$ in BSE mode at magnifications ranging from X200 to X3000.

\subsection{Cell Co-Culture Standardization and Wolbachia Production}

Once the isolation success was confirmed by optical microscopy and 16S rRNA sequencing, the infected cells were transferred into $15 \mathrm{~mL}$ cap flasks for the maintenance of isolated strain. Medium changes were performed each 15 days by centrifugation for $15 \mathrm{~min}$ at $3000 \mathrm{rpm}$ at $28{ }^{\circ} \mathrm{C}$, then the supernatant of the old medium was removed and replaced with the same volume of fresh medium. The mixture was subjected to serial gentle repeated pipetting until homogenization, then transferred to sterile cap flasks and maintained at $28^{\circ} \mathrm{C}$.

To optimize Wolbachia cell co-culture, another arthropod cell line (C6/36) derived from Aedes albopictus mosquitoes was investigated. C6/36 cell line (CRL-1660; American Type Culture Collection) was maintained in $75 \mathrm{~mL}$ cap flasks containing the Leibowitz-15 medium with L-glutamine and 
L-amino acids (Gibco ${ }^{\mathrm{TM}}$, Thermo Fisher Scientific, Inc., Waltham, MA, USA), 5\% (vol/vol) fetal bovine serum, and $2 \%$ (vol/vol) tryptose phosphate (Gibco ${ }^{\mathrm{TM}}$, Thermo Fisher Scientific, Inc., Waltham, MA, USA) at $28{ }^{\circ} \mathrm{C}$. One $\mathrm{mL}$ of a C6/36 rich cell culture was transferred to shell vial tubes $24 \mathrm{~h}$ prior to the infection. Wolbachia inoculum was obtained from a lysate of the Wolbachia S2 cells following a serial aspiration-injection into $50 \mathrm{~mL}$ falcon using a fine needle syringe. The inoculum of $200 \mu \mathrm{L}$ was used for the infection of $\mathrm{C} 6 / 36$ cells previously prepared in shell vial tubes as described above. The receptivity of C6/36 was first checked at day 15 post-infection using Diff-Quick ${ }^{\mathrm{TM}}$ staining. Once the infection was confirmed, the infected cells were transferred into $75 \mathrm{~mL}$ cap flasks containing $14 \mathrm{~mL}$ of 1 old day of C6/36 cell culture.

Bacterial growth was investigated from both infected cells under two different temperatures: $28^{\circ} \mathrm{C}$ and room temperature. Three cap flasks per each cell-line for each condition were followed for one month on the weekly schedule using the pan-Wolbachia 16S rRNA qPCR [All-Wol-16S qPCR] [68]. The repeated measures Analysis of Variance (ANOVA) was used to evaluate the effect of both temperature and cell lines on bacterial growth, while a pairwise comparison using Tukey test was performed to evaluate whether condition is more suitable. Statistical analysis were performed using XLSTAT Addinsoft version 4.1 (XLSTAT 2019: Data Analysis and Statistical Solution for Microsoft Excel, Paris, France).

\subsection{Purification of the Bacterium}

S2 cells infected with the bacterium were produced in a total volume of $75 \mathrm{~mL}$ spread over three $150 \mathrm{~cm}^{2}$ cell culture flasks. The infection rate of $97 \%$ was obtained at day 11 post-inoculation with the bacterium. Infected cells were harvested from the three flasks, then were checked for the presence of bacterial and fungal contaminations using both the Diff-Quick ${ }^{\mathrm{TM}}$ staining and the bacterial $16 \mathrm{~S}$ rRNA sequencing. The suspension was subjected to three cycles of sonication of $1 \mathrm{~min}$ at $20 \mathrm{~Hz}$, after which unlysed cells were removed by centrifugation at $500 \mathrm{rpm}$ for $10 \mathrm{~min}$. The supernatant containing the bacterium was layered onto a density gradient solution of $15 \%$ weight/volume $(\mathrm{wt} / \mathrm{vol})$ sucrose in phosphate-buffered saline (PBS, Sigma Aldrich, Saint-Quentin-Fallavier, France). After centrifugation at $9000 \times \mathrm{g}$ for $45 \mathrm{~min}$ at $4{ }^{\circ} \mathrm{C}$, the bacterium-containing pellet was resuspended in $2 \mathrm{~mL}$ of PBS and carefully layered onto a 20 to $45 \%$ (wt/vol in PBS) step density gradient. This gradient was subjected to centrifugation at $9000 \mathrm{rpm}$ for $45 \mathrm{~min}$ at $4{ }^{\circ} \mathrm{C}$; and the bacteria were harvested and washed twice in PBS, resuspended in sterile distilled water in the smallest possible volume, and then frozen at $-80^{\circ} \mathrm{C}$. At each time point, the pan-Wolbachia 16S rRNA qPCR and the Diff-Quick ${ }^{\mathrm{TM}}$ staining were performed to assess bacterial load.

\subsection{Genome Sequencing and De Novo Assembly}

Genomic DNA was extracted from $200 \mu \mathrm{L}$ of purified bacterium. The extraction was performed using QIAGEN DNA tissues kit (QIAGEN, Hilden, Germany) following the manufacturer's recommendations. An additional lysis step was applied prior to the extraction procedure using a pre-treatment by lysozyme incubation with buffer $\mathrm{G} 2$ and proteinase $\mathrm{K}$ for $2 \mathrm{~h}$ at $37^{\circ} \mathrm{C}$. The extracted gDNA was eluted in a total volume of $50 \mu \mathrm{L}$. Genomic DNA (gDNA) was quantified by a Qubit assay with the high sensitivity kit (Life technologies, Carlsbad, CA, USA); the concentration was equal to $42.86 \mathrm{ng} / \mu \mathrm{L}$. The DNA was diluted at $1 \mathrm{ng}$ as input to prepare the paired end library. The gDNA was barcoded in order to be mixed with other genomic projects with the Nextera Mate Pair sample prep kit (Illumina). The purification on AMPure XP beads (Beckman Coulter Inc. Waltham, MA, USA) was performed prior to the normalization of the libraries on specific beads according to the Nextera Mate Pair Illumina guide. Automated cluster generation and sequencing run with dual index reads were performed in a single $39 \mathrm{~h}$ run in a $2 \times 251$-bp format. Within this run, a total of 190,631 reads were generated and were quality-checked using FastQC, trimmed using Trimmomatic version 0.36.624 and assembled in seventy-eight (78) scaffolds using the SPAdes version 3.5.0 sofware25. The option "careful" was used to reduce the number of mismatches and short indels. Default Nanopore technology 
(Oxford Nanopore Technologies Ltd., Oxford, United Kingdom) was used by 1D genomic DNA sequencing on the MinION device using the SQK-LSK108 kit. The library was constructed from $1.5 \mu \mathrm{g}$ of genomic DNA without fragmentation and end repair. Adapters were ligated to both ends of genomic DNA. After purification on AMPure XP beads (Beckman Coulter Inc. Waltham, MA, USA), the library was quantified by a Qubit assay with the high sensitivity kit (Life Technologies, Cat. no. Q32856) and loaded on the flow cell via the SpotON port. A total of 466 active pores were detected for the sequencing and the workflow WIMP was chosen for sequence analysis. Adapter trimming, quality filtering and error correction of all sequencing raw data analyzed here were performed using the Trimmomatic program (version 0.36). Finally, mean read quality was 11.2 (median $=11.9$ ). A total of 78,865 reads were generated with a mean length of 1,392.9 (median 762) and an N50 read length of 2493 , which corresponds to $109,847,620$ pair bases $(\mathrm{pb})$.

\subsection{Comparative Genomic Analyses and Annotation}

First, the PL13 strain and eighteen other Wolbachia genomes were annotated using DFAST [69,70]. Numbers of orthologous proteins shared between genomes were visualized using Circos [71]. Nine Wolbachia genomes including Wolbachia supergroup A, B, C, D, E, F, L, S and an undescribed supergroup from flea [72] were selected for genomic comparisons. The circular map of the complete chromosome of PL13 strain was generated using GCviewer (http://stothard.afns.ualberta.ca/cgview server/). Annotation, completeness, and contamination values were estimated for the PL13 strain as well as the nine selected Wolbachia genomes using DFAST [69,70]. The presence of prophage regions was predicted using PHASTER [73]. Orthologous Average Nucleotide Identity (Ortho-ANI) [74] was used to evaluate the degree of genomic similarity between the PL13 strain and the other Wolbachia genomes. The pan genome distribution was evaluated using Raory software [75].

Additionally, the pervious dataset was enriched by adding four genomes representing the supergroup B, J and another undescribed supergroup from flea [72]. The Genome-to-Genome Distance Calculator Web service was used within the formula 2 to calculate the Digital DNA-DNA hybridization (dDDH) [76,77]. The probability that an intergenomic distance yielded a dDDH larger than $70 \%$, representing a novel species-delimitation threshold [78]. Similarly, the prodigual was used for prediction in the Open Reading Frame (ORF) with the default settings [79]. Deviations in the sequencing regions predicted by ORFs have been excluded. BlastP was used to predict the bacterial proteome ( $E$ value of $1 \mathrm{e} 03$, coverage of 0.7 and percent identity of 30 ) according to the Orthological Group (COG) database [80]. In the absence of match within the COG database, the BlastP was performed against the GenBank nr database [81] within an $E$ value of $1 \mathrm{e} 03$, coverage of 0.7 and $30 \%$ of identity. On the other hand, when the length of the sequence is less than 80 amino acids (aa), an $E$ value of $1 \mathrm{e} 05$ has been used. The hmmscan analysis tool [82] was used on the PFAM-A and PFAM-B domains. The assigned COGs for each genome were ordered in 26 different categories and were then compared using the Agglomerative Hierarchical Clustering (AHC) analysis. KEGG Orthology (KO) assignments was performed for the 14 Wolbachia genomes using KASS (KEGG Automatic Annotation Server) [83]. The KASS analysis was performed using BBH (bi-directional best hit) method. The assigned KO number were ordered in 177 different pathways and were then assessed using the heat map (OMICS) method. The analysis excluded all pathways that having a variance lower than 0.25 . All statistical analysis were performed using XLSTAT Addinsoft version 4.1 (XLSTAT 2019: Data Analysis and Statistical Solution for Microsoft Excel, Paris, France).

\subsection{B-Vitamins Biosynthesis Pathway}

Genes involved in the biosynthesis of B-vitamins such as the biotin (vitamin B7), riboflavin (vitamin B2), pyridoxine (vitamin B6), folate (vitamin B9) and thiamine (vitamin B1) synthesis genes were retrieved from the bedbug-Wolbachia (wClec) [59] and were used to search their homologous from the other Wolbachia genomes using Blastn. B-vitamin profile of selected Wolbachia was assessed using the AHC analysis according to the presence/absence of genes. To test whether Wolbachia 
B-vitamins synthesis genes are conserved among Wolbachia supergroups and have the same ancestors, we phylogenetically compared all B-vitamins synthesis genes presumably common within Wolbachia supergroups. This include two datasets based on the following genes: (i) FolC, $P d x J, P d x H$ and RibB from 13 Wolbachia genomes including wPpe, Wolbachia supergroup L from the earliest Wolbachia host P. penetrans (MJMG01000000) [11] and (ii) FolC, $P d x J, P d x H$, RibA, RibB, RibC, RibD, RibE and RibF from the same genome dataset except for wPpe which was excluded because it lacking for the complete gene datasets. Genes from each dataset were aligned using MAFFT [84] and concatenated within Seaview [85]. Best fit phylogenetic model was selected for each dataset and the maximum likelihood phylogeny was performed using 1000 bootstraps replicates. Molecular phylogenetic analyses were conducted on Topali v.2 software [86].

\subsection{Comparative Phylogenies and Taxonomy}

First, two single locus sequence typing (SLST) phylogenies were performed on the basis of the 16S rRNA and Wolbachia surface protein (WSP) genes. Briefly, a full-length sequence from both genes were retrieved from the annotated genome of the PL13 strain. The 16S sequences were aligned against the representative members of fifteen (A, B, C, D, E, F, H, I, J, K, L, M, N, O, and S) and two undescribed Wolbachia supergroups. While the WSP sequence of the PL13 strain was aligned against the representative members of ten Wolbachia supergroups (A, B, C, D, E, F, J, R and S) and two undescribed supergroups. All alignments were performed using the ClustalW application within Bioedit v.7.2.5. [87]. The Akaike Information Criterion (AIC) option in MEGA6 [88] was used to establish the best nucleotide substitution model for the $16 \mathrm{~S}$ sequence alignment. The Kimura 2-parameter model $(+\mathrm{G})$ [89] was selected and the maximum likelihood (ML) phylogenetic inference was used with 1000 bootstrap replicates to generate the $16 \mathrm{~S}$ tree in MEGA6 [88]. The 16 sequences from Ehrlichia chaffeensis (CP007480) and Anaplasma phagocytophilum (CP006617) were used as out groups to root the tree. The WSP phylogeny was inferred using ML method with 1000 bootstrap replicates on IQ-TREE [49]. The most appropriate model of evolution was evaluated by Modelfinder (implemented as functionality of IQ-TREE). The analysis was performed on Galaxy Australia server (https://usegalaxy.org.au/).

Genome-based phylogeny was performed for Wolbachia PL13 and 32 other complete/draft genomes of Wolbachia including nine Wolbachia supergroups: A, B, D, E, F, J, L and S and two undescribed Wolbachia to belong to any supergroup [72]. Anaplasma phagocytophilum (CP006617) and Ehrlichia chaffeensis (CP007480) genomes were included as outgroups. All genomes were aligned using the global alignment with conserved columns and gaps on Scapper software (https://github.com/tseemann/ scapper). The FASTTREE [50] was builded using ML method. GTR + CAT model was selected and the pseudocounts option was activated. This latter is recommended for highly gapped/fragmentary sequences [50]. The tree was rooted by turning on maximum-likelihood option at 1000 replicates.

Additionally, a multi loci sequence typing (MLST) phylogeny was performed on the basis of ten selected genes including: both the $16 \mathrm{~S}$ and $23 \mathrm{~S}$ ribosomal RNAs, DNA-directed RNA polymerase subunit beta $(r p o B), 60 \mathrm{kDa}$ chaperonin $(G r o L)$, cytochrome c oxidase subunit 1 (CoxA), chromosomal replication initiator protein $(D n a A)$, fructose-bisphosphate aldolase $(f b p A)$, aspartyl/glutamyl-tRNA $(A s n / G l n)$ amidotransferase subunit B (gatB), transcription termination/antitermination protein (NusA) and gamma-glutamylputrescine synthetase $(P u u A)$. The choice of these loci was conform to the standard loci requirements for an MLST system [90]. These genes were retrieved from the 35 genomes after annotation on DFAST. MAFFT alignment [84] was performed and sequences were then merged using Seaview [85]. ML phylogeny was performed with IQ-TREE [49] using 1000 bootstrap replicates. All phylograms from the SLST, MLST and FASTRTREE phylogenies were edited by iTOL v4 software [91].

\section{Conclusions}

Our results emphasize the usefulness of the S2 cells as a suitable line for the isolation and the propagation of Wolbachia. Thereby, the standardized procedure herein we proposed provided sufficient material for genome sequencing and other manipulation. This may help to resolve problems related 
to the direct sequencing of wolbachial genomes from their hosts $[7,54]$ as well as to cultivate the previously uncultivated Wolbachia (e.g., filaria-associated Wolbachia) since the S2 line allowed the successful culture of the PL13 strain in record time (11 days) despite the reduction of translational machinery of this bacteria.

Genomic and metabolic features that emphasize both nutritional-mutualistic and parasitic relationship between $w$ Chem PL13 and its host. However, the clear-cut distinction between mutualism and parasitism of this strain cannot be yet ruled out and further studies are needed.

These features provide the platform for the feature research to understand Wolbachia-host interaction. By combining bacterial isolation and taxo-genomic descriptions may ultimately assist in the quest to classify Wolbachia in multiple species as is the case of the other Rickettsiales bacterium such as Rickettsia spp. Anaplasma spp., and Ehrlichia spp.

Supplementary Materials: The following are available online at http://www.mdpi.com/1422-0067/21/21/8064/s1.

Author Contributions: Y.L., B.D., F.F. and O.M. designed the study; Y.L., performed the lab work; Y.L., M.B.K., M.M. and A.L., genomic analysis; M.S., H.B. and O.M. field investigations; Y.L., H.M., F.F., D.R. and O.M., writing-review and editing the article. All authors have read and agreed to the published version of the manuscript.

Funding: This study was supported by the Institut Hospitalo-Universitaire Méditerranée Infection, the National Research Agency under the program "Investissements d'avenir", reference ANR-10-IAHU-03, the Région Provence-Alpes-Côte d'Azur and European funding FEDER PRIMI.

Acknowledgments: We are in debt to Maxence Aubadie-Ladrix for technical assistance and Terras Jerome for taking the scanning electron microscope photographs. We are grateful for Hitachi team of Japan (Hitachi High-Technologies Corporation, Science \& Medical Systems Business Group 24-14, Tokyo, Japan) for the installation of a TM4000 microscope at the IHU Méditerranée Infection.

Conflicts of Interest: The authors declare no conflict of interest.

\section{References}

1. Hertig, M. The Rickettsia,Wolbachia pipientis (gen. et sp.n.) and Associated Inclusions of the Mosquito, Culex pipiens. Parasitology 1936, 28, 453-486. [CrossRef]

2. Zhou, W.; Rousset, F.; O'Neill, S. Phylogeny and PCR-based classification of Wolbachia strains using wsp gene sequences. Proc. R. Soc. B Boil. Sci. 1998, 265, 509-515. [CrossRef] [PubMed]

3. Khoo, J.J.; Kurtti, T.J.; Husin, N.A.; Beliavskaia, A.; Lim, F.S.; Zulkifli, M.M.S.; Al-Khafaji, A.M.; Hartley, C.; Darby, A.C.; Hughes, G.L.; et al. Isolation and Propagation of Laboratory Strains and a Novel Flea-Derived Field Strain of Wolbachia in Tick Cell Lines. Microorganisms 2020, 8, 988. [CrossRef]

4. Baldo, L.; Hotopp, J.C.D.; Jolley, K.A.; Bordenstein, S.R.; Biber, S.A.; Choudhury, R.R.; Hayashi, C.; Maiden, M.C.J.; Tettelin, H.; Werren, J.H. Multilocus Sequence Typing System for the Endosymbiont Wolbachia pipientis. Appl. Environ. Microbiol. 2006, 72, 7098-7110. [CrossRef]

5. Comandatore, F.; Cordaux, R.; Bandi, C.; Blaxter, M.; Darby, A.; Makepeace, B.L.; Montagna, M.; Sassera, D. Supergroup C Wolbachia, mutualist symbionts of filarial nematodes, have a distinct genome structure. Open Biol. 2015, 5, 150099. [CrossRef]

6. Kampfraath, A.A.; Klasson, L.; Anvar, S.Y.; Vossen, R.H.A.M.; Roelofs, D.; Kraaijeveld, K.; Ellers, J. Genome expansion of an obligate parthenogenesis-associated Wolbachia poses an exception to the symbiont reduction model. BMC Genom. 2019, 20,1-14. [CrossRef]

7. Lefoulon, E.; Clark, T.; Borveto, F.; Perriat-Sanguinet, M.; Moulia, C.; Slatko, B.E.; Gavotte, L. Pseudoscorpion Wolbachia symbionts: Diversity and evidence for a new supergroup S. BMC Microbiol. 2020, 20, 1-15. [CrossRef]

8. Bandi, C.; Anderson, T.J.C.; Genchi, C.; Blaxter, M.L. Phylogeny of Wolbachia in filarial nematodes. Proc. R. Soc. B Boil. Sci. 1998, 265, 2407-2413. [CrossRef]

9. Casiraghi, M.; Bain, O.; Guerrero, R.; Martin, C.; Pocacqua, V.; Gardner, S.L.; Franceschi, A.; Bandi, C. Mapping the presence of Wolbachia pipientis on the phylogeny of filarial nematodes: Evidence for symbiont loss during evolution. Int. J. Parasitol. 2004, 34, 191-203. [CrossRef]

10. Lefoulon, E.; Bain, O.; Makepeace, B.L.; D’Haese, C.; Uni, S.; Martin, C.; Gavotte, L. Breakdown of coevolution between symbiotic bacteria Wolbachia and their filarial hosts. PeerJ 2016, 4, e1840. [CrossRef] 
11. Brown, A.M.V.; Wasala, S.K.; Howe, D.K.; Peetz, A.B.; Zasada, I.A.; Denver, D.R. Genomic evidence for plant-parasitic nematodes as the earliest Wolbachia hosts. Sci. Rep. 2016, 6, 34955. [CrossRef]

12. Haegeman, A.; Vanholme, B.; Jacob, J.; Vandekerckhove, T.T.; Claeys, M.; Borgonie, G.; Gheysen, G. An endosymbiotic bacterium in a plant-parasitic nematode: Member of a new Wolbachia supergroup. Int. J. Parasitol. 2009, 39, 1045-1054. [CrossRef]

13. Ferri, E.; Bain, O.; Barbuto, M.; Martin, C.; Lo, N.; Uni, S.; Landmann, F.; Baccei, S.G.; Guerrero, R.; Lima, S.D.S.; et al. New Insights into the Evolution of Wolbachia Infections in Filarial Nematodes Inferred from a Large Range of Screened Species. PLoS ONE 2011, 6, e20843. [CrossRef]

14. Lefoulon, E.; Gavotte, L.; Junker, K.; Barbuto, M.; Uni, S.; Landmann, F.; Laaksonen, S.; Saari, S.; Nikander, S.; Lima, S.D.S.; et al. A new type F Wolbachia from Splendidofilariinae (Onchocercidae) supports the recent emergence of this supergroup. Int. J. Parasitol. 2012, 42, 1025-1036. [CrossRef] [PubMed]

15. Fischer, P.; Schmetz, C.; Bandi, C.; Bonow, I.; Mand, S.; Fischer, K.; Büttner, D.W. Tunga penetrans: Molecular identification of Wolbachia endobacteria and their recognition by antibodies against proteins of endobacteria from filarial parasites. Exp. Parasitol. 2002, 102, 201-211. [CrossRef]

16. Gorham, C.H.; Fang, Q.Q.; Durden, L.A. Wolbachia endosymbionts in fleas (Siphonaptera). J. Parasitol. 2003, 89, 283-289. [CrossRef]

17. Sicard, M.; Bonneau, M.; Weill, M. Wolbachia prevalence, diversity, and ability to induce cytoplasmic incompatibility in mosquitoes. Curr. Opin. Insect Sci. 2019, 34, 12-20. [CrossRef]

18. Driscoll, T.P.; Verhoeve, V.I.; Gillespie, J.J.; Johnston, J.S.; Guillotte, M.L.; Rennoll-Bankert, K.E.; Rahman, M.S.; Hagen, D.; Elsik, C.G.; Macaluso, K.R.; et al. A chromosome-level assembly of the cat flea genome uncovers rampant gene duplication and genome size plasticity. BMC Biol. 2020, 18, 1-19. [CrossRef]

19. Dittmar, K.; Whiting, M.F. New Wolbachia endosymbionts from nearctic and neotropical fleas (Siphonaptera). J. Parasitol. 2004, 90, 953-957. [CrossRef]

20. Espino, C.I.; Gómez, T.; González, G.; Santos, M.F.B.D.; Solano, J.; Sousa, O.; Moreno, N.; Windsor, D.; Ying, A.; Vilchez, S.; et al. Detection of Wolbachia Bacteria in Multiple Organs and Feces of the Triatomine Insect Rhodnius pallescens (Hemiptera, Reduviidae). Appl. Environ. Microbiol. 2008, 75, 547-550. [CrossRef]

21. Crainey, J.L.; Wilson, M.D.; Post, R.J. Phylogenetically distinct Wolbachia gene and pseudogene sequences obtained from the African onchocerciasis vector Simulium squamosum. Int. J. Parasitol. 2010, 40, 569-578. [CrossRef] [PubMed]

22. Hosokawa, T.; Koga, R.; Kikuchi, Y.; Meng, X.-Y.; Fukatsu, T. Wolbachia as a bacteriocyte-associated nutritional mutualist. Proc. Natl. Acad. Sci. USA 2009, 107, 769-774. [CrossRef]

23. Doudoumis, V.; Alam, U.; Aksoy, E.; Abd-Alla, A.M.; Tsiamis, G.; Brelsfoard, C.; Aksoy, S.; Bourtzis, K. Tsetse-Wolbachia symbiosis: Comes of age and has great potential for pest and disease control. J. Invertebr. Pathol. 2013, 112, S94-S103. [CrossRef] [PubMed]

24. Tay, S.T. Wolbachia endosymbionts, Rickettsia felis and Bartonella species, in Ctenocephalides felis fleas in a tropical region. J. Vector Ecol. 2013, 38, 200-202. [CrossRef]

25. Chaisiri, K.; McGarry, J.W.; Morand, S.; Makepeace, B.L. Symbiosis in an overlooked microcosm: A systematic review of the bacterial flora of mites. Parasitology 2015, 142, 1152-1162. [CrossRef] [PubMed]

26. Onder, Z.; Ciloglu, A.; Duzlu, O.; Yildirim, A.; Okur, M.; Yetismis, G.; Inci, A. Molecular detection and identification of Wolbachia endosymbiont in fleas (Insecta: Siphonaptera). Folia Microbiol. 2019, 64, 789-796. [CrossRef]

27. Rosselló-Mora, R.; Amann, R. The species concept for prokaryotes. FEMS Microbiol. Rev. 2001, 25, 39-67. [CrossRef]

28. Ramírez-Puebla, S.T.; Servín-Garcidueñas, L.E.; Ormeño-Orrillo, E.; De León, A.V.-P.; Rosenblueth, M.; Delaye, L.; Martinez, J.; Martínez-Romero, E. Species in Wolbachia? Proposal for the designation of 'Candidatus Wolbachia bourtzisii', 'Candidatus Wolbachia onchocercicola', 'Candidatus Wolbachia blaxteri', 'Candidatus Wolbachia brugii', 'Candidatus Wolbachia taylori', 'Candidatus Wolbachia collembolicola' and 'Candidatus Wolbachia multihospitum' for the different species within Wolbachia supergroups. Syst. Appl. Microbiol. 2015, 38, 390-399. [CrossRef] 
29. Lindsey, A.R.I.; Bordenstein, S.R.; Newton, I.L.; Rasgon, J.L. Wolbachia pipientis should not be split into multiple species: A response to Ramírez-Puebla et al., "Species in Wolbachia? Proposal for the designation of 'Candidatus Wolbachia bourtzisii', 'Candidatus Wolbachia onchocercicola', 'Candidatus Wolbachia blaxteri', 'Candidatus Wolbachia brugii', 'Candidatus Wolbachia taylori', 'Candidatus Wolbachia collembolicola' and 'Candidatus Wolbachia multihospitum' for the different species within Wolbachia supergroups". Syst. Appl. Microbiol. 2016, 39, 220-222. [CrossRef]

30. Weeks, A.R.; Breeuwer, J.A.J. Wolbachia-induced parthenogenesis in a genus of phytophagous mites. Proc. R. Soc. B Boil. Sci. 2001, 268, 2245-2251. [CrossRef]

31. Hornett, E.A.; Duplouy, A.M.R.; Davies, N.; Roderick, G.K.; Wedell, N.; Hurst, G.D.D.; Charlat, S. You can't keep a good parasite down: Evolution of a male-killer suppressor uncovers cytoplasmic incompatibility. Evol. Int. J. Org. Evol. 2008, 62, 1258-1263. [CrossRef] [PubMed]

32. Werren, J.H.; Baldo, L.; Clark, M.E. Wolbachia: Master manipulators of invertebrate biology. Nat. Rev. Genet. 2008, 6, 741-751. [CrossRef] [PubMed]

33. Kern, P.; Cook, J.M.; Kageyama, D.; Riegler, M. Double trouble: Combined action of meiotic drive and Wolbachia feminization in Eurema butterflies. Biol. Lett. 2015, 11, 20150095. [CrossRef] [PubMed]

34. Fenn, K.; Blaxter, M. Wolbachia genomes: Revealing the biology of parasitism and mutualism. Trends Parasitol. 2006, 22, 60-65. [CrossRef]

35. Pike, N.; Kingcombe, R. Antibiotic treatment leads to the elimination of Wolbachia endosymbionts and sterility in the diplodiploid collembolan Folsomia candida. BMC Biol. 2009, 7, 54. [CrossRef]

36. Bourtzis, K.; Dobson, S.L.; Xi, Z.; Rasgon, J.L.; Calvitti, M.; Moreira, L.A.; Bossin, H.C.; Moretti, R.; Anthony, L.; Hughes, G.L.; et al. Acta Tropica Harnessing mosquito-Wolbachia symbiosis for vector and disease control. Acta Trop. 2014, 132, S150-S163. [CrossRef]

37. Bouchery, T.; Lefoulon, E.; Karadjian, G.; Nieguitsila, A.; Martin, C. The symbiotic role of Wolbachia in Onchocercidae and its impact on filariasis. Clin. Microbiol. Infect. 2013, 19, 131-140. [CrossRef]

38. Kamtchum-Tatuene, J.; Makepeace, B.L.; Benjamin, L.; Baylis, M.; Solomon, T. The potential role of Wolbachia in controlling the transmission of emerging human arboviral infections. Curr. Opin. Infect. Dis. 2017, 30, 108-116. [CrossRef]

39. Hughes, G.L.; Rasgon, J.L. Transinfection: A method to investigate Wolbachia-host interactions and control arthropod-borne disease. Insect Mol. Biol. 2013, 23, 141-151. [CrossRef]

40. Fisher, M.L.; Watson, D.W.; Osborne, J.A.; Mochizuki, H.; Breen, M.; Schal, C. Growth kinetics of endosymbiont Wolbachia in the common bed bug, Cimex lectularius. Sci. Rep. 2018, 8, 11444. [CrossRef]

41. Meriweather, M.; Matthews, S.; Rio, R.; Baucom, R.S. A 454 Survey Reveals the Community Composition and Core Microbiome of the Common Bed Bug (Cimex lectularius) across an Urban Landscape. PLoS ONE 2013, 8, e61465. [CrossRef]

42. Akhoundi, M.; Cannet, A.; Loubatier, C.; Berenger, J.-M.; Izri, A.; Marty, P.; Delaunay, P. Molecular characterization of Wolbachia infection in bed bugs (Cimex lectularius) collected from several localities in France. Parasite 2016, 23. [CrossRef] [PubMed]

43. Moriyama, M.; Nikoh, N.; Hosokawa, T.; Fukatsu, T. Riboflavin provisioning underlies Wolbachia's fitness contribution to its insect host. MBio 2015, 6. [CrossRef] [PubMed]

44. Kimura, M. Estimation of evolutionary distances between homologous nucleotide sequences. Proc. Natl. Acad. Sci. USA 1981, 78, 454-458. [CrossRef] [PubMed]

45. Waddell, P.J.; Steel, M. General Time-Reversible Distances with Unequal Rates across Sites: Mixing $\Gamma$ and Inverse Gaussian Distributions with Invariant Sites. Mol. Phylogenet. Evol. 1997, 8, 398-414. [CrossRef] [PubMed]

46. Bordenstein, S.R.; Rosengaus, R.B. Discovery of a Novel Wolbachia Supergroup in Isoptera. Curr. Microbiol. 2005, 51, 393-398. [CrossRef]

47. Glowska, E.; Dragun-Damian, A.; Dabert, M.; Gerth, M. New Wolbachia supergroups detected in quill mites (Acari: Syringophilidae). Infect. Genet. Evol. 2015, 30, 140-146. [CrossRef]

48. Stackebrandt, E. Taxonomic parameters revisited: Tarnished gold standards. Microbiol. Today 2006, 33, 152-155.

49. Nguyen, L.-T.; Schmidt, H.A.; Von Haeseler, A.; Minh, B.Q. IQ-TREE: A Fast and Effective Stochastic Algorithm for Estimating Maximum-Likelihood Phylogenies. Mol. Biol. Evol. 2014, 32, 268-274. [CrossRef] 
50. Price, M.N.; Dehal, P.S.; Arkin, A.P. FastTree 2-Approximately Maximum-Likelihood Trees for Large Alignments. PLoS ONE 2010, 5, e9490. [CrossRef]

51. O'Neill, S.L.; Pettigrew, M.M.; Sinkins, S.P.; Braig, H.R.; Andreadis, T.G.; Tesh, R.B. In vitro cultivation of Wolbachia pipientis in an Aedes albopictus cell line. Insect Mol. Biol. 1997, 6, 33-39. [CrossRef] [PubMed]

52. Fenollar, F.; La Scola, B.; Inokuma, H.; Dumler, J.S.; Taylor, M.J.; Raoult, D. Culture and Phenotypic Characterization of a Wolbachia pipientis Isolate. J. Clin. Microbiol. 2003, 41, 5434-5441. [CrossRef] [PubMed]

53. Hague, M.T.J.; Caldwell, C.N.; Cooper, B.S. Divergent effects of Wolbachia on host temperature preference. bioRxiv 2020, 59812. [CrossRef]

54. Lefoulon, E.; Vaisman, N.; Frydman, H.M.; Sun, L.; Voland, L.; Foster, J.M.; Slatko, B.E. Large Enriched Fragment Targeted Sequencing (LEFT-SEQ) Applied to Capture of Wolbachia Genomes. Sci. Rep. 2019, 9, 5939. [CrossRef] [PubMed]

55. Lefoulon, E.; Clark, T.; Guerrero, R.; Cañizales, I.; Cardenas-Callirgos, J.M.; Junker, K.; Vallarino-Lhermitte, N.; Makepeace, B.L.; Darby, A.C.; Foster, J.M.; et al. Diminutive, degraded but dissimilar: Wolbachia genomes from filarial nematodes do not conform to a single paradigm. bioRxiv 2020, 3, 1-45. [CrossRef]

56. Lindsey, A.R.I.; Werren, J.H.; Richards, S.; Stouthamer, R. Comparative Genomics of a Parthenogenesis-Inducing Wolbachia Symbiont. G3 Genes Genomes Genet. 2016, 6, 2113-2123. [CrossRef]

57. Foster, J.; Ganatra, M.; Kamal, I.; Ware, J.; Makarova, K.; Ivanova, N.; Bhattacharyya, A.; Kapatral, V.; Kumar, S.; Posfai, J.; et al. The Wolbachia Genome of Brugia malayi: Endosymbiont Evolution within a Human Pathogenic Nematode. PLoS Biol. 2005, 3, e121. [CrossRef]

58. Wang, N.; Jia, S.; Xu, H.; Liu, Y.; Huang, D.W. Multiple Horizontal Transfers of Bacteriophage WO and Host Wolbachia in Fig Wasps in a Closed Community. Front. Microbiol. 2016, 7, 136. [CrossRef]

59. Nikoh, N.; Hosokawa, T.; Moriyama, M.; Oshima, K.; Hattori, M.; Fukatsu, T. Evolutionary origin of insect-Wolbachia nutritional mutualism. Proc. Natl. Acad. Sci. USA 2014, 111, 10257-10262. [CrossRef]

60. Balvín, O.; Roth, S.; Talbot, B.; Reinhardt, K. Co-speciation in bedbug Wolbachia parallel the pattern in nematode hosts. Sci. Rep. 2018, 8, 8797. [CrossRef]

61. Akman, L.; Yamashita, A.; Watanabe, H.; Oshima, K.; Shiba, T.; Hattori, M.; Aksoy, S. Genome sequence of the endocellular obligate symbiont of tsetse flies, Wigglesworthia glossinidia. Nat. Genet. 2002, 32, $402-407$. [CrossRef] [PubMed]

62. Schneider, I. Cell lines derived from late embryonic stages of Drosophila melanogaster. J. Embryol. Exp. Morphol. 1972, 27, 353-365. [PubMed]

63. Maina, A.N.; Luce-Fedrow, A.; Omulo, S.; Hang, J.; Chan, T.-C.; Ade, F.; Jima, D.D.; Ogola, E.; Ge, H.; Breiman, R.F.; et al. Isolation and characterization of a novel Rickettsia species (Rickettsia asembonensis sp. nov.) obtained from cat fleas (Ctenocephalides felis). Int. J. Syst. Evol. Microbiol. 2016, 66, 4512-4517. [CrossRef] [PubMed]

64. Luce-Fedrow, A.; Macaluso, K.R.; Richards, A.L. Growth of Rickettsia felis in Drosophila melanogaster S2 Cells. Vector-Borne Zoonotic Dis. 2014, 14, 101-110. [CrossRef]

65. Mediannikov, O.; Matsumoto, K.; Samoylenko, I.; Drancourt, M.; Roux, V.; Rydkina, E.; Davoust, B.; Tarasevich, I.; Brouqui, P.; Fournier, P.-E. Rickettsia raoultii sp. nov., a spotted fever group rickettsia associated with Dermacentor ticks in Europe and Russia. Int. J. Syst. Evol. Microbiol. 2008, 58, 1635-1639. [CrossRef]

66. Diop, A.; Barker, S.C.; Eberhard, M.; Barker, D.; Nguyen, T.T.; Di Pinto, F.; Raoult, D.; Mediannikov, O. Rickettsia fournieri sp. nov., a novel spotted fever group rickettsia from Argas lagenoplastis ticks in Australia. Int. J. Syst. Evol. Microbiol. 2018, 68, 3781-3784. [CrossRef]

67. Weisburg, W.G.; Barns, S.M.; A Pelletier, D.; Lane, D.J. 16 S ribosomal DNA amplification for phylogenetic study. J. Bacteriol. 1991, 173, 697-703. [CrossRef]

68. Laidoudi, Y.; Davoust, B.; Varloud, M.; Niang, E.H.A.; Fenollar, F.; Mediannikov, O. Development of a multiplex qPCR-based approach for the diagnosis of Dirofilaria immitis, D. repens and Acanthocheilonema reconditum. Parasites Vectors 2020, 13, 319. [CrossRef]

69. Tanizawa, Y.; Fujisawa, T.; Kaminuma, E.; Nakamura, Y.; Arita, M. DFAST and DAGA: Web-based integrated genome annotation tools and resources. Biosci. Microbiota Food Health 2016, 35, 173-184. [CrossRef]

70. Tanizawa, Y.; Fujisawa, T.; Nakamura, Y. DFAST: A flexible prokaryotic genome annotation pipeline for faster genome publication. Bioinformatics 2017, 34, 1037-1039. [CrossRef]

71. Krzywinski, M.; Schein, J.; Birol, I.; Connors, J.; Gascoyne, R.; Horsman, D.; Jones, S.J.; Marra, M.A. Circos: An information aesthetic for comparative genomics. Genome Res. 2009, 19, 1639-1645. [CrossRef] [PubMed] 
72. Driscoll, T.P.; Verhoeve, V.I.; Gillespie, J.J.; Johnston, J.S.; Guillotte, M.L.; Rennoll-Bankert, K.E.; Rahman, M.S.; Hagen, D.; Elsik, C.G.; Macaluso, K.R.; et al. Cat fleas in flux: Rampant gene duplication, genome size plasticity, and paradoxical Wolbachia infection. bioRxiv 2020. [CrossRef]

73. Arndt, D.; Grant, J.R.; Marcu, A.; Sajed, T.; Pon, A.; Liang, Y.; Wishart, D.S. PHASTER: A better, faster version of the PHAST phage search tool. Nucleic Acids Res. 2016, 44, W16-W21. [CrossRef] [PubMed]

74. Lee, I.; Kim, Y.O.; Park, S.-C.; Chun, J. OrthoANI: An improved algorithm and software for calculating average nucleotide identity. Int. J. Syst. Evol. Microbiol. 2016, 66, 1100-1103. [CrossRef] [PubMed]

75. Page, A.J.; Cummins, C.A.; Hunt, M.; Wong, V.K.; Reuter, S.; Holden, M.T.; Fookes, M.; Falush, D.; Keane, J.A.; Parkhill, J. Roary: Rapid large-scale prokaryote pan genome analysis. Bioinformatics 2015, 31, 3691-3693. [CrossRef] [PubMed]

76. Auch, A.F.; Von Jan, M.; Klenk, H.-P.; Göker, M. Digital DNA-DNA hybridization for microbial species delineation by means of genome-to-genome sequence comparison. Stand. Genom. Sci. 2010, 2, 117-134. [CrossRef]

77. Auch, A.F.; Klenk, H.-P.; Göker, M. Standard operating procedure for calculating genome-to-genome distances based on high-scoring segment pairs. Stand. Genom. Sci. 2010, 2, 142-148. [CrossRef]

78. Meier-Kolthoff, J.P.; Auch, A.F.; Klenk, H.-P.; Göker, M. Genome sequence-based species delimitation with confidence intervals and improved distance functions. BMC Bioinform. 2013, 14, 60. [CrossRef]

79. Hyatt, D.; Chen, G.-L.; Locascio, P.F.; Land, M.L.; Larimer, F.W.; Hauser, L.J. Prodigal: Prokaryotic gene recognition and translation initiation site identification. BMC Bioinform. 2010, 11, 119. [CrossRef]

80. Tatusov, R.L.; Galperin, M.Y.; Natale, D.A.; Koonin, E.V. The COG database: A tool for genome-scale analysis of protein functions and evolution. Nucleic Acids Res. 2000, 28, 33-36. [CrossRef]

81. A Benson, D.; Cavanaugh, M.; Clark, K.; Karsch-Mizrachi, I.; Ostell, J.; Pruitt, K.D.; Sayers, E.W. GenBank. Nucleic Acids Res. 2017, 46, D41-D47. [CrossRef] [PubMed]

82. Finn, R.D.; Clements, J.; Eddy, S.R. HMMER web server: Interactive sequence similarity searching. Nucleic Acids Res. 2011, 39 (Suppl. 2), W29-W37. [CrossRef] [PubMed]

83. Moriya, Y.; Itoh, M.; Okuda, S.; Yoshizawa, A.C.; Kanehisa, M. KAAS: An automatic genome annotation and pathway reconstruction server. Nucleic Acids Res. 2007, 35, W182-W185. [CrossRef] [PubMed]

84. Katoh, K. MAFFT: A novel method for rapid multiple sequence alignment based on fast Fourier transform. Nucleic Acids Res. 2002, 30, 3059-3066. [CrossRef]

85. Gouy, M.; Guindon, S.; Gascuel, O. SeaView Version 4: A Multiplatform Graphical User Interface for Sequence Alignment and Phylogenetic Tree Building. Mol. Biol. Evol. 2009, 27, 221-224. [CrossRef] [PubMed]

86. Milne, I.; Lindner, D.; Bayer, M.; Husmeier, D.; McGuire, G.; Marshall, D.F.; Wright, F. TOPALi v2: A rich graphical interface for evolutionary analyses of multiple alignments on HPC clusters and multi-core desktops. Bioinformatics 2008, 25, 126-127. [CrossRef] [PubMed]

87. Hall, T.; Biosciences, I.; Carlsbad, C. BioEdit: An important software for molecular biology. GERF Bull. Biosci. 2011, 2, 60-61.

88. Tamura, K.; Stecher, G.; Peterson, D.; Filipski, A.; Kumar, S. MEGA6: Molecular evolutionary genetics analysis version 6. Mol. Biol. Evol. 2013, 30, 2725-2729. [CrossRef]

89. Kimura, M. A simple method for estimating evolutionary rates of base substitutions through comparative studies of nucleotide sequences. J. Mol. Evol. 1980, 16, 111-120. [CrossRef]

90. Lorenzo-Carballa, M.O.; Torres-Cambas, Y.; Heaton, K.; Hurst, G.; Charlat, S.; Sherratt, T.N.; Van Gossum, H.; Cordero-Rivera, A.; Beatty, C.D. Widespread Wolbachia infection in an insular radiation of damselflies (Odonata, Coenagrionidae). Sci. Rep. 2019, 9, 1-13. [CrossRef]

91. Letunic, I.; Bork, P. Interactive Tree Of Life (iTOL) v4: Recent updates and new developments. Nucleic Acids Res. 2019, 47, W256-W259. [CrossRef] [PubMed]

Publisher's Note: MDPI stays neutral with regard to jurisdictional claims in published maps and institutional affiliations. 